\title{
Environmental and Socioeconomic Impacts of Poly(ethylene terephthalate) (PET) Packaging Management Strategies in the EU
}

\author{
Bassi, Susanna Andreasi; Tonini, Davide; Saveyn, Hans; Astrup, Thomas Fruergaard
}

Published in:

Environmental Science and Technology

Link to article, DOI:

10.1021/acs.est.1c00761

Publication date:

2022

Document Version

Publisher's PDF, also known as Version of record

Link back to DTU Orbit

Citation (APA):

Bassi, S. A., Tonini, D., Saveyn, H., \& Astrup, T. F. (2022). Environmental and Socioeconomic Impacts of Poly(ethylene terephthalate) (PET) Packaging Management Strategies in the EU. Environmental Science and Technology, 56(1), 501-511. https://doi.org/10.1021/acs.est.1c00761

\section{General rights}

Copyright and moral rights for the publications made accessible in the public portal are retained by the authors and/or other copyright owners and it is a condition of accessing publications that users recognise and abide by the legal requirements associated with these rights.

- Users may download and print one copy of any publication from the public portal for the purpose of private study or research.

- You may not further distribute the material or use it for any profit-making activity or commercial gain

- You may freely distribute the URL identifying the publication in the public portal 


\title{
Environmental and Socioeconomic Impacts of Poly(ethylene terephthalate) (PET) Packaging Management Strategies in the EU
}

\author{
Susanna Andreasi Bassi,* Davide Tonini, Hans Saveyn, and Thomas Fruergaard Astrup
}

Cite This: https://doi.org/10.1021/acs.est.1c00761

Read Online

ACCESS

Lلll Metrics \& More

Article Recommendations

Supporting Information

ABSTRACT: Plastics are a challenge for the circular economy due to their overall low recycling rate and high dependency on primary resources. This study analyzes the EU demand for poly(ethylene terephthalate) (PET) packaging from 2020 to 2030 and quantifies the potential environmental and societal savings by changing the waste management and consumption patterns compared with business-as-usual practices. The results of the life-cycle assessment and life-cycle costing show that a maximum of $38 \mathrm{Mt}$ of $\mathrm{CO}_{2}$-eq and $34 \mathrm{kt}$ of $\mathrm{PM}_{2.5}$-eq could be saved with a more efficient waste management system and a robust secondary material market while also avoiding 8.3 billion $\mathrm{EUR}_{2019}$ in societal costs (cumulative 2020-2030). However, limiting annual PET consumption growth

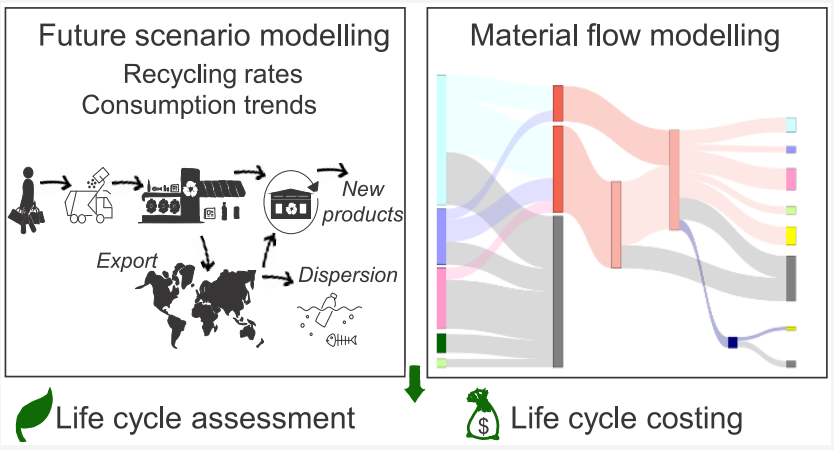
appears to have a similar profound effect on improving the efficiency of waste management systems: $35 \mathrm{Mt}$ of $\mathrm{CO}_{2}$-eq, $31 \mathrm{kt}$ of $\mathrm{PM}_{2.5}$-eq, and 25 billion $\mathrm{MEUR}_{2019}$ societal costs could be saved, simply by keeping EU consumption of PET constant.

KEYWORDS: life-cycle assessment (LCA), life-cycle costing (LCC), sustainability assessment, plastic consumption, waste management, recycling

\section{INTRODUCTION}

The development of plastics has progressed rapidly. The first synthetic material was invented in $1855,{ }^{1}$ in 1963 we were already living in the "Age of Plastics", 2 and production increased from 1.5 Mt in 1950 to $348 \mathrm{Mt}$ in 2017 . $^{3}$ Currently, the petrochemical sector accounts only for $14 \%$ of global daily oil consumption, ${ }^{4}$ but it will account for more than $30 \%$ of the growth in oil demand in 2030 and almost $50 \%$ in $2050^{5}$ due to the decreased oil demand in the energy sector. Plastics have been defined both as a "miraculous substance" 6 and one of the symbols of the negative anthropogenic impacts on the environment due to the high quantities found in many ecosystems ${ }^{7,8}$ aligned with their low overall recycling rate and low degradability under natural conditions. The consequences of the 2018 Chinese regulation on imported low-quality plastics revealed key weaknesses in the Western recycling system $^{9,10}$ that was dependent on the export of almost $50 \%$ of the overall collected plastic waste. ${ }^{10}$ In recent years, plastic recycling and more generally circular economy seemed to provide a solution to decouple environmental impacts and economic/consumption growth and to reduce our dependency on fossil resources. ${ }^{11}$ At the same time, closed-loop recycling of plastic was promoted as a more environmentally friendly option than open-loop recycling.

Several studies have utilized life-cycle assessment (LCA) to evaluate the environmental performance of plastic waste management systems and demonstrated that plastic recycling is generally preferable to incineration or landfilling in most of environmental impact categories (notably climate change). ${ }^{12-18}$ Yet, recent plastic flow studies have stressed that the overall (also called end-of-life) recycling rates of the European Union (EU) are currently poor (ca. 14\% ${ }^{19,20}$ ) and several technological and financial developments are thus needed to reach the 50-55\% recycling targets of the EU by 2025 and 2030. ${ }^{21}$ However, traditional LCAs $^{22-25}$ often assume that all secondary materials are recycled into new products, without quantifying whether a market exists and is indeed able to absorb this additional secondary material (i.e., without analyzing the market size and response). In addition, they rarely quantify the difference between closed-loop and open-loop recycling, the analyses are usually performed at a local level and not on the EU scale, ${ }^{18}$ and they seldom include the effect of exporting waste outside Europe or the risk of plastic leakage to the environment, even though EU exported more than 1.8 Mt of plastic waste to non-European countries

Received: February 2, 2021

Revised: September 3, 2021

Accepted: November 5, 2021 
in $2019 .^{26}$ Moreover, no previous study has quantified the collection rate needed to increase the recycled content in specific products, as envisioned by the EU legislation. ${ }^{27}$

Overall, there is a research gap in terms of coupling traditional life-cycle assessments with regional mass balances and market analysis to investigate the role of waste management, end-market for secondary material, and consumption, in terms of environmental and economic impacts.

Here, we analyzed the EU poly(ethylene terephthalate) (PET) packaging consumption between 2020 and 2030 by employing both life-cycle assessment and costing (LCA and LCC) methodologies. PET was chosen because it is the most recycled $^{28}$ and most common polymer ${ }^{20}$ found in household waste. The objective is to quantify the net variation of environmental emissions and societal costs caused by changing the business-as-usual waste management and consumption trends, thereby highlighting potential improvements and environmental risks. The geographical scope is the EU27 plus Norway, Switzerland, and the UK, from now on referred to simply as "the EU".

\section{METHODS}

Goal and Scope. The aim of the study was to compare the environmental and economic performances of different waste management alternatives relative to the business-as-usual (BAU) situation. The functional unit was the EU consumption of PET packaging between 2020 and 2030, and the management of the waste generated from such demand. Considering the consumption (in addition to the annual PET waste generated) allows testing the environmental performance of the system under prevention scenarios. The analysis was performed with a "cradle-to-grave" perspective, ${ }^{29}$ including resource extraction, PET packaging manufacturing, and waste management. PET packaging was divided into five subfractions (clear bottles, colored bottles, trays, flexible packaging, and strapping) characterized by different yearly generation rates, collection methods, collection rates, level of maturity of the recycling industry, potential flake usage, and end-markets (for details see the Supporting Information A). For each subfraction, we first modeled the full mass balance assuming that waste management between 2020 and 2030 remained the same as 2020, which represented the BAU situation. Note that the majority of data for 2020 were projections based on previous years due to the lack of data specifically for 2020 . Second, we quantified the environmental and economic changes induced by eight different waste management alternatives, i.e., all results were calculated as the difference between the alternatives and the BAU.

The environmental assessment complied with life-cycle assessment (LCA) ISO standards, ${ }^{30-32}$ and the economic assessment adhered to the life-cycle costing methodology (LCC). ${ }^{33,34}$ The LCA and LCC shared the same goal and scope, system boundaries, and modeling approach, ${ }^{35}$ and were performed using the software ${ }^{36,37}$ (selected because of its capabilities of keeping mass, substance, and energy balance throughout the system), and Ecoinvent 3.5-consequential for the background processes. ${ }^{38}$ We applied a consequential approach $^{39,40}$ because we aimed at studying the consequences of changing the current status of PET packaging waste management and marginal technologies were calculated for sections of the system that were only marginally affected by the modeled changes ${ }^{39}$ (e.g., electricity, industrial heating, space heating). Finally, multifunctional activities were solved through the use of system expansion, ${ }^{30-32}$ meaning that we subtracted both the environmental impact and the cost of the energy that would have to be produced without waste incineration, and that of the products made of primary PET that would have been produced without recycling (impact/cost of producing primary PET granules + impact/cost of manufacturing packaging products). A detailed explanation of system expansion (also called substitution in the literature) can be found in Weidema. ${ }^{41}$ No market substitution factor was implemented: $1 \mathrm{~kg}$ of secondary PET used in fibers and strapping avoided $1 \mathrm{~kg}$ of primary PET, ${ }^{18}$ while $1 \mathrm{~kg}$ of bottlegrade primary granules is avoided when flakes are extruded (for trays) and solid-state polymerized (for bottles). However, we accounted for market demand and saturation, meaning that a given end-market cannot absorb more secondary material than the consumers' demand of that market. When the market was saturated, the secondary material was either absorbed by another market or exported.

In the LCA, we calculated the 22 impact categories recommended in $\mathrm{ReCiPe} 2016 \mathrm{v1.1},{ }^{42,43}$ and after a normalization and weighting step, the two most relevant impact categories (i.e., contributing to $80-90 \%$ to the single endpoint environmental indicator) appeared to be global climate change $(\mathrm{CC})^{44}$ and particulate matter formation (PMF), ${ }^{45}$ as shown in the Results and Discussion section. The results for all of the impact categories are anyway reported in the Supporting Information $\mathrm{B}$. We also tested how much the result of the CC was affected by assigning different characterization factors to fossil $\mathrm{CO}_{2}$ and to biogenic $\mathrm{CO}_{2}$ emitted in different years. ${ }^{46,47}$ However, since the effect of this methodological change caused a variation lower than $5 \%$, we decided not to include it in the illustrated results and to assign instead a characterization factor equal to 1 to fossil $\mathrm{CO}_{2}$ and equal to 0 to biogenic $\mathrm{CO}_{2}$ independently from the year.

The cost model included three different types of costs: budget costs, transfers, and externalities. ${ }^{35}$ Budget costs are internal costs incurred by different actors in the PET value chain (e.g., municipalities, waste collectors, recyclers, etc.). Transfers refer to money that is simply redistributed among stakeholders: direct taxes, indirect taxes (e.g., VAT), and fees (e.g., landfill fee). Externalities are nonmonetary transactions and represent the costs that each emission into the air, water, and soil cause to society. The price of the externalities was based on the CE Delft report. ${ }^{48}$ The conventional LCC (budget cost + transfer) describes the financial cost of the functional unit, while the societal LCC (budget costs expressed as shadow costs + externality) is useful for understanding which costs are carried by the society. Budget costs were transformed into shadow costs by multiplying them by 1.325 . $^{49}$ No discounting or inflation was applied to costs or externalities occurring in the future. All economic data found in the literature were adjusted for inflation to $\mathrm{EUR}_{2019}$ using the Harmonized Indices of Consumer Prices, ${ }^{50}$ and all capital investments were amortized by assuming a $5 \%$ interest rate, and a 20-year lifetime for buildings and between 5 and 8 years for equipment. ${ }^{51}$ Finally, the economic assessment also allows for estimating the job creation/reduction potentials of different alternatives relative to the BAU, quantified as full-time employees (FTE).

The mass balance, alongside environmental and economic impacts, is shown without considering impurities in the sourceseparated material and PET bales, albeit impurities were considered when compiling the data inventories (see the 


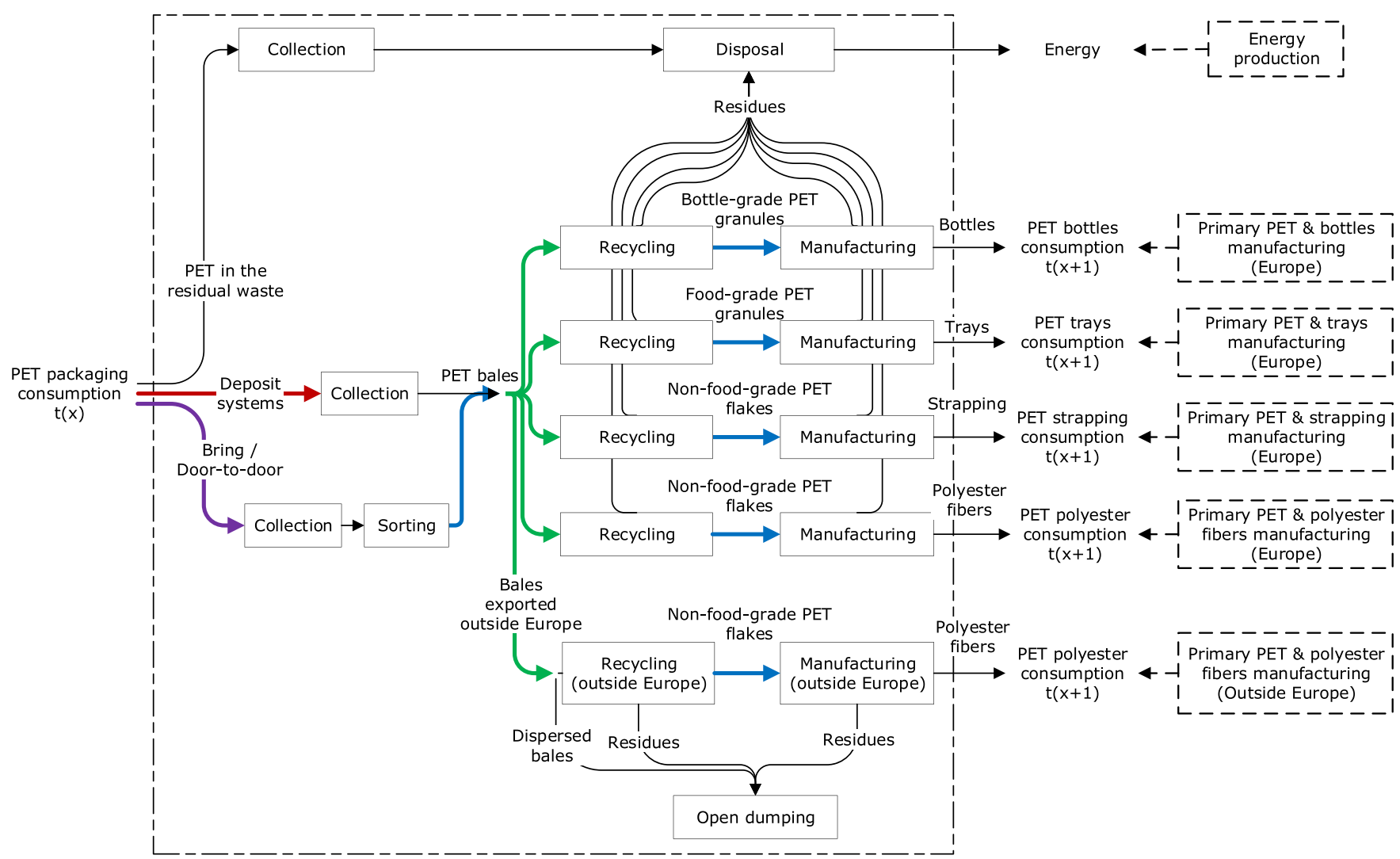

Figure 1. System boundaries of the life-cycle assessment (LCA) and life-cycle costing (LCC). All flows indicate a change in the mass since the results are calculated as a difference in flows between the modeled scenario and the business-as-usual (BAU) waste management. The colored arrows indicate flows affected by different waste management alternatives: increasing collection rates for bottles with deposit systems (red arrow), increasing collection rate for trays (violet arrow), increasing sorting and plant recycling rates (blue arrows), and changing PET end-markets (green arrows).

Supporting Information A). Hereafter, the term "collection rate" indicates the $\mathrm{kg}$ of PET packaging collected per $\mathrm{kg}$ of PET packaging waste generated (both without accounting for impurities), and "sorting rate" refers to the $\mathrm{kg}$ of PET packaging in the PET bale per kg of PET packaging entering the sorting plant (both without accounting for impurities). Furthermore, the "plant recycling rate" refers to the efficiency of the recycling plants and was calculated as the $\mathrm{kg}$ of secondary material produced (e.g., flakes or granules) per kg of input PET bale (without accounting for impurities). Finally, the "end-of-life recycling rate" was calculated as $\mathrm{kg}$ of PET packaging in PET bales (without accounting for impurities) per $\mathrm{kg}$ of PET packaging waste generated since it was the closest approximation to the updated requirements of the European Commission. $^{21}$

System Boundaries. Figure 1 shows the system boundaries of the analysis: demand, collection, sorting, recycling, and manufacturing. The EU packaging consumption quantifies the input mass in each year that becomes waste in the same year since packaging has a lifetime shorter than 1 year. ${ }^{52}$ PET bottles are source-separated via either deposit systems or traditional bring/door-to-door systems, together with other plastic polymers and sometimes with metals, while PET trays can be collected only by bring/door-to-door systems. The term "bring system" is used when large waste containers for different waste fractions are placed at public places, and "door-to-door system" is when the waste bins are collected in front or very close to residential houses (equal to "kerbside" in the UK literature). ${ }^{53}$ The difference between deposit systems and bring/door-to-door system is that the former is more expensive and does not typically need a sorting step because there are fewer impurities. No separate collection was modeled for strapping and flexible materials, i.e., they are assumed to be collected with mixed waste and sent to incineration or landfilling. PET collected via bring/door-todoor source-separation is then transported to a material recovery facility that is responsible for sorting the plastics into different bales, which are then sold to recyclers. We simplified the recyclers with one stakeholder responsible for transforming the plastic bale into a secondary material that can be used in new manufacturing processes. Recycling is a complex, multistep process that varies depending on the desired output. $^{54,55}$ In this study, we modeled three different recycling processes depending on the desired output of recycling: if the secondary material was used in polyester and strapping manufacturing, the plastic bales had to be sorted, washed, and shredded obtaining PET flakes; if the target was PET tray manufacturing, an additional extrusion step was added to produce food-grade PET granules; if the target was PET bottle manufacturing, the extrusion was followed by solid-state polymerization (SSP) supplying food-grade granules with increased molecular weight. The recycling pathways indicate the percentage of each bale that ends up in a particular endmarket, thus requiring a different recycling process, and they were calculated differently in each alternative to study the effect of the market on the results. Thereafter, the secondary material recycled in the EU is transported to a manufacturing industry that produces new plastic packaging or polyester 
fibers, which in turn are shipped to final consumers. Manufacturing was assumed to be the same for products made from primary and secondary PET. The plastic collected with mixed waste and residues from sorting/recycling/ manufacturing was sent for either incineration or landfilling. The percentage of waste sent to incineration compared with landfilling was modeled to linearly increase from 57\% in 2017 (incineration rate in all of the EU countries weighted with the PET bottle consumption ${ }^{56}$ ) to $82 \%$ in 2030 (assuming that all EU countries respected the EU limit to landfill a maximum of $10 \%$ in $2035^{57}$ ). While acknowledging that different projections may be performed, the EU acquis (current and under revision; e.g., Waste Shipment Regulation) clearly pushes toward the ban on landfilling and export to non-OECD countries, which will inevitably increase the share of incineration (in addition to recycling).

Generally, we assumed that the quantity of secondary material produced cannot be higher than the demand for the specific product in the following year, multiplied by their maximum recycled content. The fraction of PET bales not recycled in the EU is subsequently exported to Hong Kong, India, Indonesia, Malaysia, Thailand, Turkey, and Vietnam (importers of EU plastic waste in 2018 and $2019^{26}$ ), where between $18 \%$ and $88 \%$ of the plastics ends up littered or inadequately disposed of. ${ }^{7}$ To quantify the risk of environmental dispersion, often highlighted in the literature, ${ }^{21,27,58}$ we assumed that $70 \%$ of the exported waste was lost in the environment, thereby keeping the range of $18-88 \%$ in the uncertainty distribution. Waste landfilling in countries importing the waste (for both the dispersed waste and the residues from recycling and manufacturing) was assumed to be in an open dump with no additional costs or employment. Capital goods and transport were always included. Finally, each year was characterized by different collection rates, sorting rates, plant recycling rates, recycling pathways, marginal energy mix, and ratio between incineration and landfilling of the residues. The comprehensive explanation of the assumptions, process modeling, uncertainty ranges, detailed budget costs, transfers, and full-time equivalent employees for each process (collection, sorting, recycling, manufacturing, incineration, landfilling, etc.) can be found in the Supporting Information A.

Waste Management Alternatives. We modeled and compared the BAU with eight different future waste management alternatives:

(I) High collection rate for bottles-The collection rate for bottles gradually increases from $59.4 \%$ in the BAU to $77 \%$ in 2025 and to $90 \%$ in 2029 , as expressed in the EU Directive $2019 / 904,{ }^{27}$ by incrementing the percentage of bottles collected via deposit systems from $23 \%$ in the BAU to $100 \%$ in 2029 . We modeled the same recycling pathways as in the BAU, and $5 \%$ of the clear bottle bales and $25 \%$ of colored bottle bales are exported (as in the BAU).

(II) High collection rate for trays-The collection rate for PET trays increases from $20 \%$ in the BAU to $87 \%$ in 2030 (87\% represents the highest collection rate of bottles achieved in the EU in 2017 without a deposit system $^{59}$ ). We modeled the same recycling pathways as in the BAU.

(III) High sorting and plant recycling rates-EU countries increase the sorting rate for bottles by $1 \%$ yearly (from $80 \%$ in the BAU 2020 to $89 \%$ in 2030 ), the sorting rate for trays by $4 \%$ yearly to reach the same rate as bottles in the BAU (from 34\% in the BAU 2020 to $80 \%$ in $2030)$, and the plant recycling rates by $0.5 \%$ yearly $^{23}$ (from $81 \%$ in the BAU 2020 to $85 \%$ in 2030). This alternative quantifies the qualitative improvements mentioned in the European strategy for plastics for sorting and recycling plants. ${ }^{10}$ We modeled the same recycling pathways as in the BAU.

(IV) $100 \%$ to fibers-The PET packaging market does not request any secondary PET, and the polyester industries have become the only end-market. When the demand for secondary PET saturates the EU market for polyester, excess PET bales are exported outside the EU. This alternative illustrates, for example, a situation in which the packaging market is flooded with cheap primary materials.

(V) $100 \%$ to strict closed-loop-All secondary PET is used in the packaging industry by implementing measures that support closed-loop recycling (PET from clear bottles is used for new clear bottles, colored bottles into new colored bottles, trays into new trays) following the recent pledges of PET associations and PET bottle manufacturers. ${ }^{60,61}$

(VI) Improved system $+100 \%$ to fibers-The system is improved by combining the measures in (I), (II), and (III). The secondary PET is modeled as in (IV).

(VII) Improved system $+100 \%$ to a strict closed-loop-The system is improved by combining the measures in (I), (II), and (III). The secondary PET is modeled as in (V), assuming that no PET bale is exported because EU recyclers are able to absorb all of the produced secondary material.

(VIII) Linear system for PET packaging-All of the waste is simply collected with the mixed waste and sent to incineration or landfilling as before 2000 when the quantity of plastic being recycled was almost negligible. ${ }^{62}$ The proportion to incineration and landfilling is described under "System boundaries".

Uncertainty and Framework Scenario Analysis. The robustness of the results was tested with both uncertainty analysis and framework scenario analysis. The uncertainty analysis was divided into uncertainty propagation and global sensitivity analysis. ${ }^{63}$ First, the model was fully parametrized, and the 130 parameters describing ancillary materials, energy consumption, and costs were given an uncertainty distribution (described in the Supporting Information A) that was then propagated by a Monte Carlo analysis. ${ }^{64}$ The uncertainty distributions were based on an extensive literature review and are described in detail in the Supporting Information A and the results of the uncertainty propagation are illustrated in Figures 3 and 4 as the $95 \%$ confidence interval obtained by the Monte Carlo analysis (Figures 3 and 4). Second, the results of the global sensitivity analysis allowed us to quantify which parameters contributed the most to the uncertainty of the total results. Furthermore, the results were tested in a framework scenario analysis where: (i) the annual growth rate was assumed to be $0 \%$ and the annual PET packaging consumption was assumed to be equal to the projected demand in 2020 throughout the entire period (2020-2030) studied (no trade-off with other materials was considered because PET bottle consumption per capita appears to be more dependent on cultural habits and running water quality 


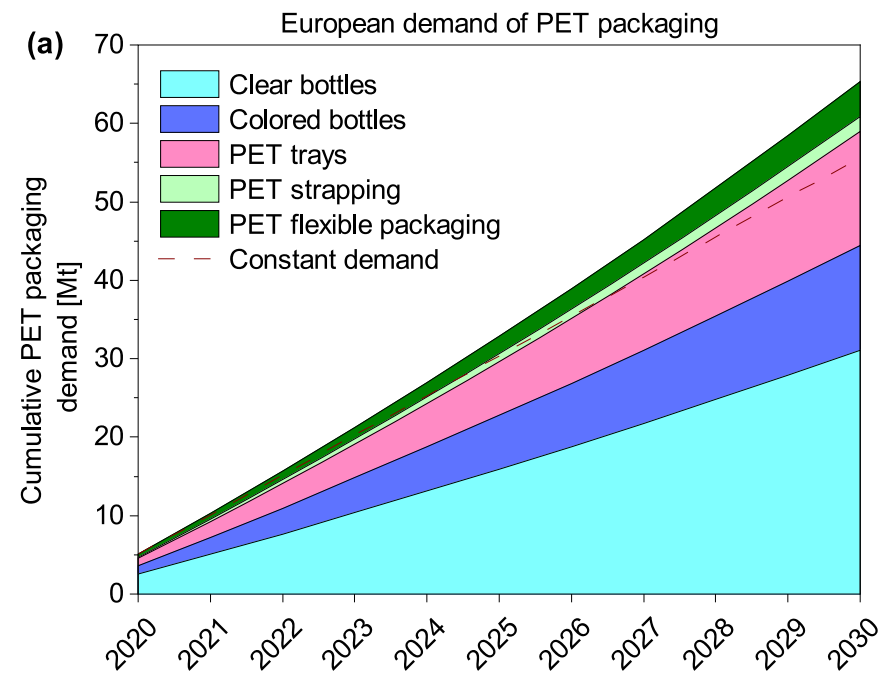

(b)

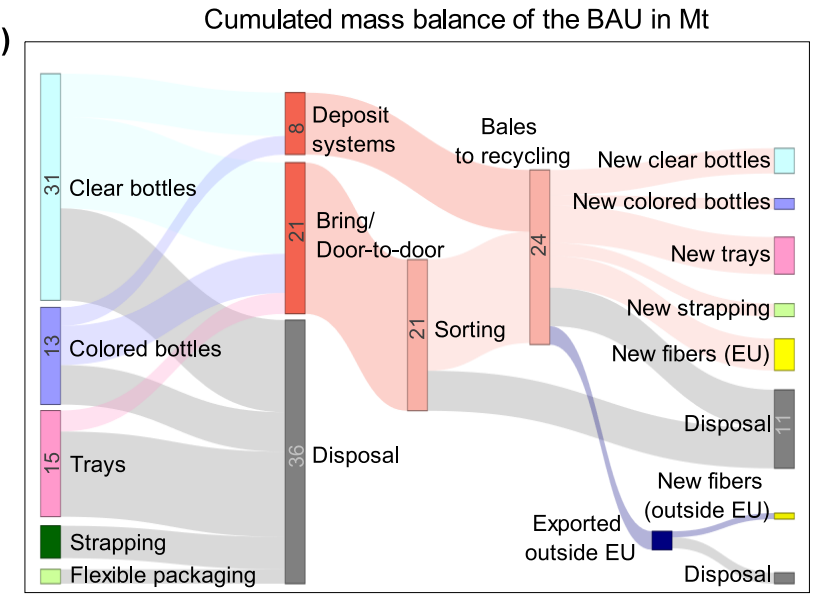

Figure 2. Expected EU demand for PET packaging (a) and Sankey diagrams of the PET packaging waste management system in Mt, keeping waste management as the business-as-usual (BAU) (b). Both results are cumulatively calculated between 2020 and 2030 and are shown without impurities.

than to GDP or wealth ${ }^{59}$ ); (ii) the EU market for polyester increased the recycled content from the current $14 \%{ }^{65}$ to $50 \%$, thus allowing for more secondary PET to be absorbed by the polyester manufacturers before being exported; (iii) the avoided/induced energy in each year was assumed to be the average energy forecasted in the Geco2018 NDC scenario ${ }^{66}$ instead of the marginal; (iv) the avoided/induced primary PET was assumed to be manufactured outside the EU instead of in the EU; and (v) the avoided/induced primary PET was assumed to be made of bio ethylene glycol instead of fossil ethylene glycol. ${ }^{67}$

\section{RESULTS AND DISCUSSION}

PET Packaging in the Business-as-Usual Scenario. The cumulative EU PET packaging demand from 2020 to 2030 is estimated at $63 \mathrm{Mt}$ (Figure 2a), with yearly consumption increasing from 5.1 Mt (in 2020) to $6.9 \mathrm{Mt}$ (in 2030). When considering BAU consumption growth and waste management (Figure 2b), the EU is expected to collect for recycling $26 \mathrm{Mt}$ of bottles (of which $8.5 \mathrm{Mt}$ is through deposit systems) and 2.7 Mt of trays for recycling, and $24 \mathrm{Mt}$ of bales for recycling. PET packaging $(36 \mathrm{Mt})$ is expected to end up in mixed waste.

If we assume that $11 \%$ of the PET bales is exported out of the EU (as in 2017; ref 68), the remaining $89 \%$ is recycled in the EU and used to manufacture $3.4 \mathrm{Mt}$ of clear bottles, $1.5 \mathrm{Mt}$ of colored bottles, 5.1 Mt of PET trays, $1.8 \mathrm{Mt}$ of strapping, and $4.3 \mathrm{Mt}$ of polyester fibers that would otherwise have used primary PET. This is equal to $18 \mathrm{Mt}$ of primary PET total (considering manufacturing losses), corresponding to $12 \mathrm{Mt}$ of oil and 2.9 Mt of natural gas for the feedstock. All in all, an end-of-life recycling rate in the BAU will reach $51 \%$ for bottles in 2030 and $7 \%$ for PET trays, totaling an end-of-life recycling rate of 33\% for PET packaging.

Environmental Impacts. As described in the Methods section, climate change (CC), quantified in $\mathrm{kg} \mathrm{CO}_{2}$-eq and shown in Figure 3a and particulate matter formation (PMF), quantified in $\mathrm{kg} \mathrm{PM}_{2.5}$-eq and shown in Figure $3 \mathrm{~b}$, are the most relevant environmental impact categories after weighting the 22 impact categories of ReCiPe2016. The results of all of the midpoint and endpoint impact categories can be found in the Supporting Information B. In this section, we refer to a generic "environmental impact or environmental benefit" when both CC and PMF show the same result.

Both impact categories show that PET recycling is generally better than incineration or landfilling. Among alternatives I, II, and III, increasing the collection rate of bottles (alternative I) assures the highest environmental benefits, saving an additional $21 \mathrm{Mt}$ of $\mathrm{CO}_{2}$-eq and $10 \mathrm{kt}$ of $\mathrm{PM}_{2.5}$-eq, and will result in an end-of-life recycling rate of $54 \%$ in 2030 . If collection, sorting, and plant recycling rates are increased simultaneously (alternatives VI and VII), the EU will be able to collect an additional $14 \mathrm{Mt}$ of PET packaging for recycling between 2020 and 2030, and the difference between the results depends on which end-market absorbs the secondary PET. In the best-case scenario (alternative VII), the production of an additional 14 Mt of secondary granules (including PET produced in both $\mathrm{EU}$ and Asia) corresponds to the total EU consumption for 3 consecutive years, thus saving an extra $38 \mathrm{Mt}$ of $\mathrm{CO}_{2}$-eq and 34 $\mathrm{kt}$ of $\mathrm{PM}_{2.5}$-eq and the refining extra $9.4 \mathrm{Mt}$ of oil and $2.3 \mathrm{Mt}$ of natural gas. This means that the EU could reduce the consumption of fossil fuels allocated for PET packaging production by $50 \%$ when comparing the BAU with alternative VII in the year 2030 , and by $30 \%$ for the cumulative period 2020-2030. In this perspective, the $38 \mathrm{Mt}$ of $\mathrm{CO}_{2}$-eq. achieved only from PET management corresponds to the $\mathrm{CO}_{2}$-eq emissions from about ca. $5 \mathrm{M}$ people. As recent studies have indicated that EU through recycling (of all) plastic waste could at most achieve an additional annual saving of ca. 14-20 Mt of $\mathrm{CO}_{2}$-eq, ${ }^{69}$ the savings from improved PET management could constitute a significant saving. Alternative VII also shows that the highest end-of-life recycling rate of PET packaging (including bottles, trays, flexible packaging, and strapping) could increase from the current $35 \%$ (2020) to $76 \%$ in 2030 (more precisely $90 \%$ for PET bottles and 70\% for PET trays). This result highlights the challenges the EU will face to reach its ambitious $55 \%$ recycling target for plastic packaging by $2030^{21}$ without unleashing the potential of PET trays, ${ }^{68}$ which will likely increase from constituting $20 \%$ of the whole PET packaging in 2020 to $25 \%$ in 2030 . 
(a)

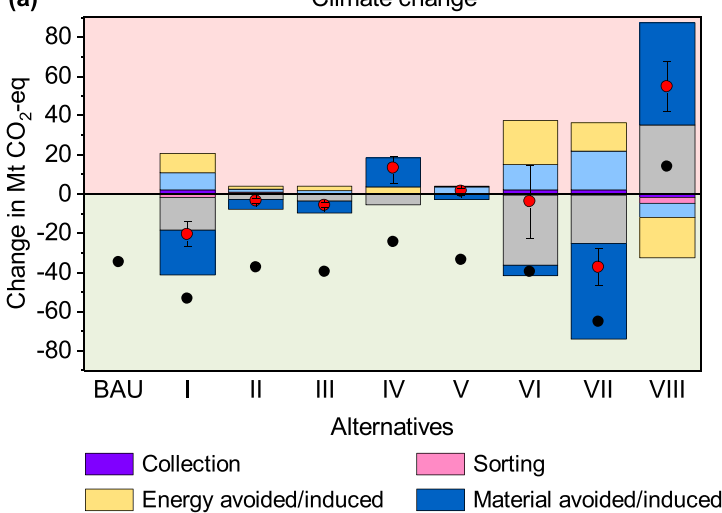

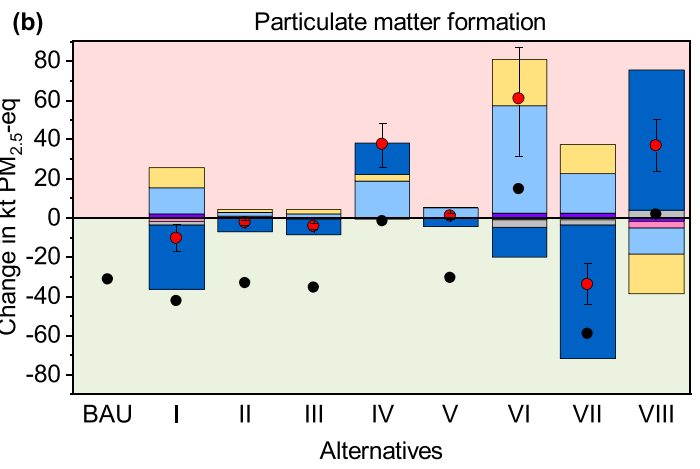

Recycling \& Manufacturing - Total
- Constant consumption
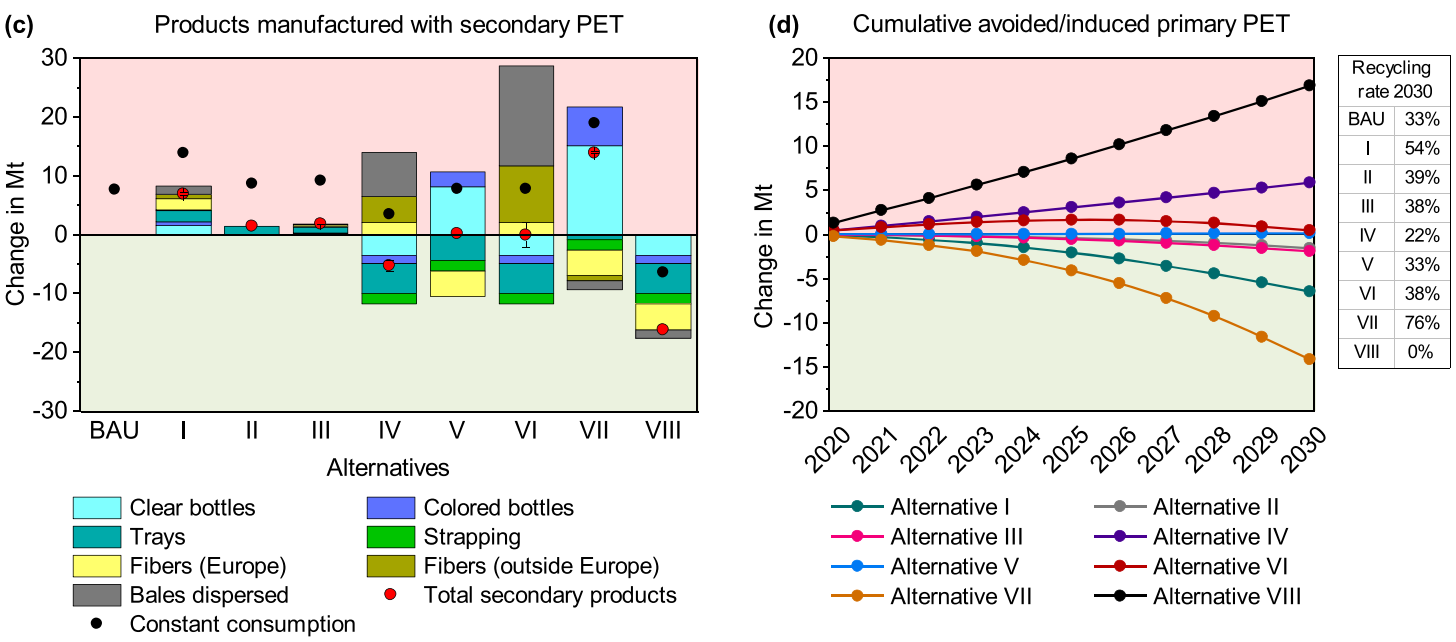

Figure 3. Cumulative change in climate change (a), particulate matter formation (b), plastic products made with secondary PET (c), and primary PET granules demanded following recycling (d). All results are cumulative between 2020 and 2030, calculated as differences from the business-asusual (BAU) scenario (represented by the zero line) with a 95\% confidence interval. The results in the green area represent a lower environmental impact than in the BAU in (a) and (b) and higher material avoidance in (c) and (d). In (a) and (b), "collection" includes all of the collection activities and transport to the sorting plant (when needed); "sorting" refers to sorting activities and transport to the recyclers; "recycling and manufacturing" represent recycling and manufacturing activities and transport from recyclers to manufacturers, and from manufacturers to final consumers; "incineration and landfilling" relates to direct emissions from incineration and landfilling and transport to the incineration or landfilling sites; "avoided/induced products" is the production of primary PET granules, the manufacturing of products and transport to manufacturers and final consumers; "avoided/induced energy" refers to electricity and space heating production. Roman numerals represent the analyzed alternatives. I: higher collection rate for bottles; II: higher collection rate for trays; III: higher sorting and plant recycling rates, IV: $100 \%$ to fibers; V: $100 \%$ to strict closed-loop; VI: combined I, II, III, and IV; VII: combined I, II, III, and V; and VIII: linear system. The only result of the framework scenario analysis illustrated is the total for the constant consumption $(\bullet)$ because it is the most relevant for the interpretation of the results (all other scenarios can be found in the Supporting Information B). Note that the graphs have different units. Results per annum are available in the Supporting Information B.

When assuming that PET packaging does not absorb any secondary PET and the only possible end-market is polyester fiber production (alternatives IV and VI), the EU polyester market would be already saturated in the year 2020 (i.e., the EU polyester manufacturers do not need as much secondary PET as the packaging waste could generate). In this case, an additional $13 \mathrm{Mt}$ (IV) and $29 \mathrm{Mt}$ (VI) of PET bales would probably be exported, thus incurring the risk of dispersing 7.6 (IV) and $17 \mathrm{Mt}$ (VI) of PET packaging waste and producing 5.8 Mt (IV) and 0.5 Mt (VI) less secondary PET compared with BAU. This in turn highlights that the creation of a market for secondary material is as important as increasing the quantity of PET collected. Finally, the collapse of the recycling system (alternative VIII; linear system) would cause an additional $55 \mathrm{Mt}$ of $\mathrm{CO}_{2}$-eq and $37 \mathrm{kt}$ of $\mathrm{PM}_{2.5}$-eq, mainly through missed recycling potential since the $18 \mathrm{Mt}$ of primary
PET currently saved in the BAU would be produced from virgin sources.

Figure 3 a shows that the major contributions to $\mathrm{CC}$ are the direct $\mathrm{CO}_{2}$-fossil emissions from incineration $\left(2.5 \mathrm{~kg}\right.$ of $\mathrm{CO}_{2}$ fossil emission per $\mathrm{kg}$ of plastic incinerated), the avoided PET products made from primary granules, the induced energy (when less plastic is sent for incineration, the energy previously generated will have to be produced elsewhere), and the industrial heat consumption in recycling and manufacturing. A similar analysis could be carried out for the impact category of PMF apart from two aspects: plastic incineration with energy recovery is always a net benefit in the case of PMF (because direct emissions are offset by credits from the avoided energy), and the shipping of the exported material is an important source of these emissions. 
(a)

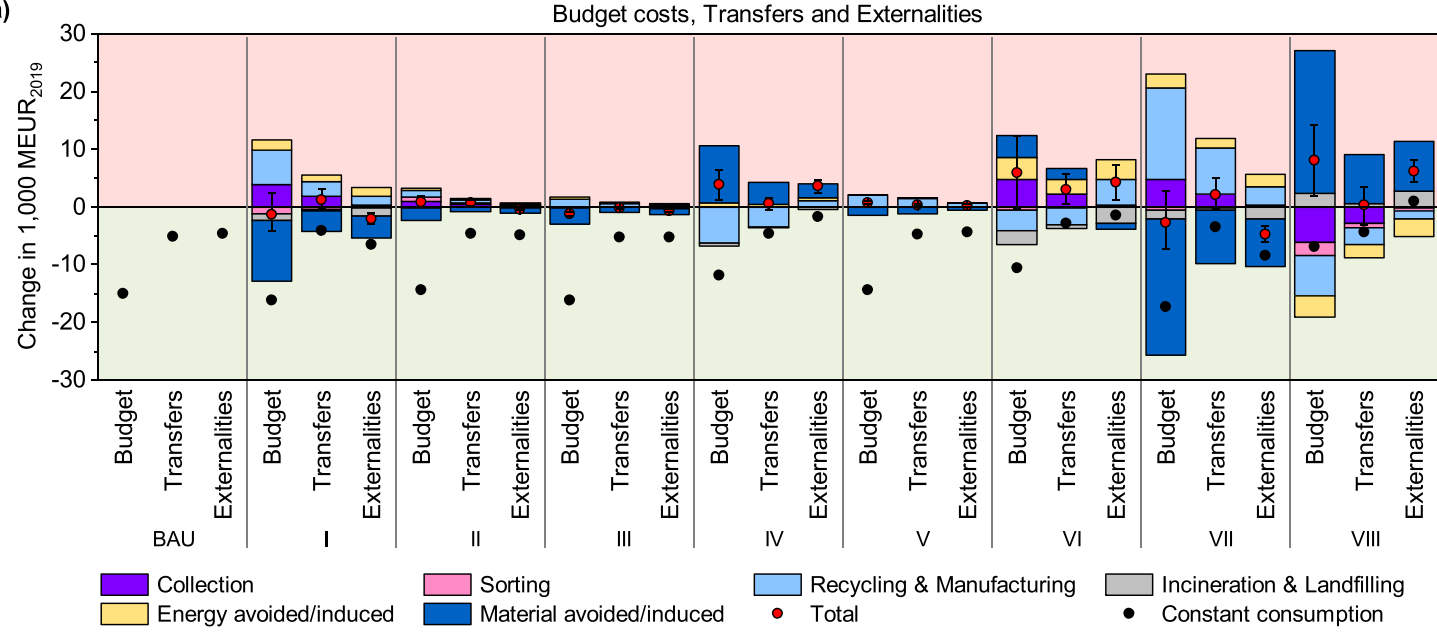

(b)

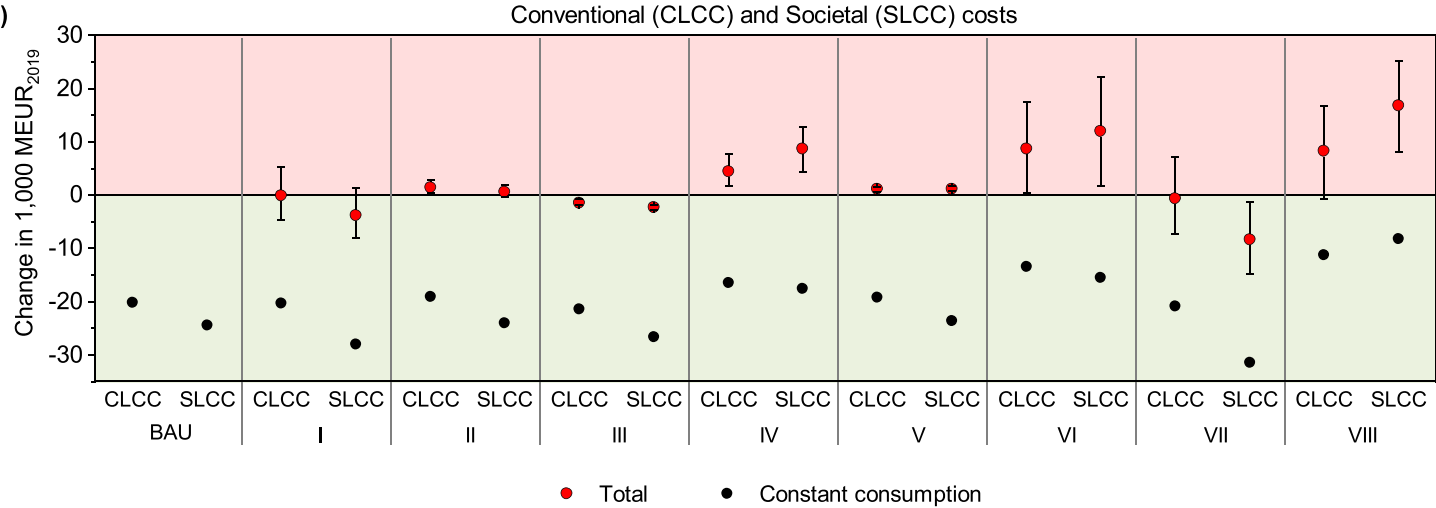

Figure 4. Contribution analysis of budget costs, transfers, and externalities (a) and final results for the conventional (CLCC) and societal life-cycle cost (SLCC) (b). All results are cumulative between 2020 and 2030 and calculated as differences from the business-as-usual (BAU) scenario (represented by the zero line) with a $95 \%$ confidence interval. The results in the green area represent lower costs or lower externalities. The Roman numerals represent the analyzed alternatives I: higher collection rate for bottles; II: higher collection rate for trays; III: higher sorting and plant recycling rates, IV: $100 \%$ to fibers; V: $100 \%$ to strict closed-loop; VI: combined I, II, II and IV; VII: combined I, II, III, and V; and VIII: linear system. The only result of the framework scenario analysis illustrated is the total for the constant consumption $(\bullet)$ because it is the most relevant for the interpretation of the results (all other scenarios can be found in the Supporting Information B). Results per annum are available in the Supporting Information B.

The majority of alternatives do not overlap when considering the $95 \%$ confidence interval (uncertainty bars in Figure $3 \mathrm{a}, \mathrm{b})$, thus revealing that the conclusions are mainly independent of the uncertainty of the single parameters. The results from the global sensitivity analysis revealed that most of the uncertainties are associated with the energy efficiency of incineration plants and in particular the possibility of being connected to a district heating system and avoiding space heating. The detailed results of the uncertainty propagation and the global sensitivity analysis can be found in the Supporting Information B.

The framework scenario analysis confirms the ranking of the alternatives while still providing some additional information about the importance of the framework conditions (detailed results for all of the scenarios are to be found in the Supporting Information B). By far the most significant variant in terms of impact is the yearly growth of EU PET packaging consumption: an additional $35 \mathrm{Mt}$ of $\mathrm{CO}_{2}$-eq and $31 \mathrm{kt}$ of $\mathrm{PM}_{2.5}$-eq are saved when the consumption is kept constant between 2020 and 2030 (see • in Figure 3) under BAU waste management. This result alone is better than almost all of the alternatives with growing consumption, excluding VII. Our results thus show the pivotal importance of combining prevention with recycling toward the achievement of the EU Green Deal ambitions. Furthermore, by combining a constant consumption and alternative VII, we observe the benefit of an additional $65 \mathrm{Mt}$ of $\mathrm{CO}_{2}$-eq and $59 \mathrm{kt}$ of $\mathrm{PM}_{2.5}$-eq saved relative to the BAU. As expected, alternatives IV and VI are strongly dependent on the assumptions behind the market saturation of secondary PET for EU polyester industries. If a major effort is put into polyester manufacturing, to increase the maximum recycled content from the current $14-50 \%$, scenario IV would perform similar to $\mathrm{V}$ (strict closed-loop) and the BAU. However, without this precondition, current efforts to keep secondary PET from packaging within the same packaging industry should be supported.

Role of PET Packaging in the Circular Economy: the Secondary Material Markets. The detailed study of recycling pathways, outlining the products in which the secondary raw material is absorbed, has highlighted the importance of the market. No environmental benefit will be achieved without a market demand that is able to absorb secondary materials, even if the material is source-separated, collected, and sorted. This means that it is as important to look 
at the market size as it is to examine environmental savings potential. For example, recycling PET in food-grade granules for tray manufacturing appears to decrease $\mathrm{CC}$ and PMF by $12 \%$ relative to recycling PET in bottle-grade granules for bottle manufacturing, as high-energy intensive solid-state polymerization is not required. Similarly, recycling PET in non-food-grade flakes for fiber manufacturing appears to decrease emissions by $13 \%$ for $\mathrm{CO}_{2}$-eq and $3 \%$ for $\mathrm{PM}_{2.5}$-eq relative to bottle-grade granules. However, these potential savings do not account for the actual regional end-market: the EU polyester market will only absorb $690 \mathrm{kt}$ of secondary flakes in 2030 (assuming a recycled content of 14\%), which equates to the flakes generated from $38 \%$ of the bottle bales produced in 2029 (in the BAU), meaning that the polyester market could not physically absorb more, even if it was environmentally beneficial to do so, without considerably increasing the recycled content of both staple fibers and filaments. At the same time, to ensure that the PET bottles have at least $30 \%$ recycled plastics by 2030 - as envisioned in Directive $2019 / 904^{27}$ - ca. 1.4 Mt of bottle-grade granules needs to be produced in 2030, equaling $70 \%$ of the bottles collected through BAU waste management. Focusing only on recycled content without increasing the collection rate would likely cause a drop in the recycled content in trays, strapping, and polyester, as the feedstock would be simply diverted to bottle manufacturing. The need for a stronger connection between end-of-life recycling rate and recycled content has also been highlighted in recent LCA methodological papers ${ }^{70-72}$ and we hope that future studies will explore it for different products and materials.

Conventional and Societal Costs. Budget costs, transfers (direct and indirect taxes), and externalities are illustrated in Figure 4a. The confidence intervals are relatively higher than for environmental impacts due to both intrinsic variations among different EU states and the sensitivity of economic data to economies of scale (lower costs for larger facilities).

Compared with the environmental results, collection is much more significant, while sorting, incineration, and landfilling are almost negligible. Budget costs are generally negative (profit) in alternatives I (higher collection rate for bottles), III (higher sorting and plant recycling rates), and VII (combined alternatives I, II, III + strict closed-loop), but most transfers are positive. On the other hand, externalities show a result in line with CC and PMF, have smaller relative uncertainty, and are mostly associated with air emissions in the form of carbon dioxide, particulate matter smaller than 2.5 $\mu \mathrm{m}\left(\mathrm{PM}_{2.5}\right)$, nitrogen oxides, and sulfur dioxide. During the 2020-2030 period, the potential reduction of externalities will range from 410 MEUR $_{2019}$ (alternative II) to 4700 MEUR $_{2019}$ (alternative VII); in contrast, relying only on polyester as an end-market for secondary PET incurs additional externalities equal to 3600 (IV) and 4300 (VI) MEUR 2019 due to higher quantities of material being exported and lost, while a completely linear system (alternative VIII) causes an additional 6200 MEUR $_{2019}$, mostly owing to emissions from primary plastic production to fulfill consumption.

Figure $4 \mathrm{~b}$ illustrates the aggregated costs (budget, transfer, externalities) as conventional LCC (CLCC) and societal LCC (SLCC). Increasing the collection rate of PET bottles (I) results in a net saving of 110 MEUR $_{2019}$ in the CLCC and 3800 MEUR $_{2019}$ in the SLCC. Increasing the sorting and plant recycling rates of the technologies (III) leads to a net saving of 1400 MEUR $_{2019}$ and 2300 MEUR $_{2019}$ in the CLCC and SLCC, respectively. The best alternative (VII) generates 630 and 8300 MEUR $_{2019}$ savings in the CLCC and SLCC, respectively. All of the remaining alternatives show an economic loss (positive CLCC): alternative II (high collection rate of trays) mainly because of the inefficient sorting system for PET trays, while the alternatives involving a high amount of exported bales (IV and VI) incur net additional costs because of the high quantity of material collected and sorted but not sold as secondary material.

When analyzing the uncertainty of the results, the conventional LCC results in a saving (negative result) in 56\% (I) and $59 \%$ (VII) of the Monte Carlo iterations (i.e., the 95\% confidence interval falls in both the positive and negative $y$ axis). The global sensitivity analysis reveals that this large variation is mainly due to the uncertainty of the cost of separate collection: we calculate that bottle recycling can be economically feasible if the cost of bring/door-to-door collection stays below $370 \mathrm{EUR}_{2019} / \mathrm{t}$ and the cost of deposit systems is below $555 \mathrm{EUR}_{2019} / \mathrm{t}$. Another relevant parameter of the global sensitivity analysis is the market price of primary PET (more information in the Supporting Information B) here estimated to be $825-1400 \mathrm{EUR}_{2019} / \mathrm{t}$. The detailed results of the uncertainty propagation and of the global sensitivity analysis can be found in the Supporting Information B.

Finally, to calculate the net job creation/loss, we added new jobs (e.g., in collection, sorting, and recycling) and subtracted avoided jobs (e.g., in incineration or landfilling facilities and in the primary plastic production industry), estimating that over 113000 new jobs could be additionally created between 2020 and 2030 for alternative I and between 158000 and 168000 for alternative VII. A linear system without recycling (alternative VIII) leads to a net decrease of 173000 jobs relative to the BAU. At the same time, the framework scenario with constant consumption and BAU waste management causes the potential loss of 160000 jobs relative to BAU. This finding, while signaling the challenge of reducing consumption and maintaining jobs does not account for any job reallocation.

Risk of Plastic Export. The previous results show that measures to increase PET collection and plant efficiency should synchronize through a more holistic approach, including the establishment of a robust EU recycling industry for PET (that is directly linked to the design of PET products) and the creation of stable end-markets for secondary materials. Differently, the EU will simply increase the quantity of bales being incinerated or exported to low- and medium-income countries. We calculated that between 2020 and 2030, $2.5 \mathrm{Mt}$ of PET bales may be shipped to non-European countries with a high amount of plastics discarded or inadequately disposed of, and $30 \%$ of the exported bales realistically entering non-EU recycling plants (see the Methods section). Although this paper does not provide any proof that a part of the exported PET bales is not recycled, it highlights the known risk of exporting plastics from high-income countries with very developed waste management systems to low-income countries. Our study did not include any additional externality for the dispersion of plastic in the environment because this is still under research. However, recent studies have quantified that the societal cost of marine plastic debris is between 2200 and 33000 USD per ton. ${ }^{73,74}$ If we apply the average (16 000 $\mathrm{EUR}_{2019} / \mathrm{t}$ ) to the dispersed PET bales in the BAU in 2020 $(0.12 \mathrm{Mt})$, assuming that between 15 and $40 \%$ of non-recycled plastics could enter the ocean, ${ }^{7}$ we deduce that EU PET in 2020 alone incurs an externality of 290-770 $\mathrm{MEUR}_{2019}$, 
totaling 3600-9600 MEUR $_{2019}$ of damage in the cumulative period 2020-2030. In addition to the risk of environmental dispersion, there are other reasons to reduce plastic exportation: plastic consumption in the developing world is increasing, ${ }^{75,76}$ thereby putting more stress on less welldeveloped plastic management systems and the number of countries banning or restricting plastic waste is increasing. ${ }^{77,78}$ Methodological guidance on how to include waste dispersion in LCA results is expected in the following years and will help in achieving consistency on how environmental studies are presented to policy-makers and the public audience.

Role of Consumption. The previous sections highlight that substantial environmental savings, expressed either in terms of environmental impacts or externalities, are possible by improving the waste management value chain-as anticipated also by many stakeholders investing in the plastic circular economy. ${ }^{10,27,79}$ However, our results show that reducing the environmental impacts of growing consumption is challenging, even if waste management is improved since the majority of alternatives result in greater environmental impacts compared with maintaining constant consumption. For example, in 2030, with an efficient waste management and secondary PET utilization (alternative VII) of $6.9 \mathrm{Mt}$ of PET packaging waste generated, the EU could save an additional 7.3 $\mathrm{Mt}$ of $\mathrm{CO}_{2}$-eq relative to BAU. Yet, $6.8 \mathrm{Mt}$ of $\mathrm{CO}_{2}$-eq could be avoided by simply keeping 2030 PET consumption at 2020 levels, and up to $12 \mathrm{Mt}$ of $\mathrm{CO}_{2}$-eq if this were coupled with an efficient waste management policy. This suggests that high consumption with efficient waste management systems does not necessarily result in lower environmental impacts compared with low consumption and weak recycling. It should be noted that we did not model any rebound effect for avoided consumption, and we do not advocate the use of other materials instead of plastics (proved to be potentially counterproductive ${ }^{80}$ ); instead, we assume that a reduction in PET packaging would be possible following a change in consumer habits, justified by the fact that the per capita consumption of bottled water or soda varies greatly among EU countries. ${ }^{59}$ The same connection between consumption patterns, efficiency, and environmental impact was also confirmed from the results of other macroeconomic models. ${ }^{81}$

\section{ASSOCIATED CONTENT}

\section{SI Supporting Information}

The Supporting Information is available free of charge at https://pubs.acs.org/doi/10.1021/acs.est.1c00761.

Detailed life-cycle inventory for the collection, sorting, recycling, manufacturing, and production of primary $\mathrm{PET}$, and the result of the mass balance for all of the alternatives (Supporting Information A) (PDF)

Recycling pathways per year and per waste fraction; recycled content and end-of-life recycling rate; LCA results (characterized midpoint of $\mathrm{CC}$ and PMF, midpoint and endpoint impacts calculated with $\mathrm{ReC}$ iPe2016), LCC results (budget costs, transfers, externalities, conventional and societal LCC, full-time equivalent employees), and global sensitivity analysis (list of parameters contributing to the overall uncertainty) (Supporting Information B) (XLSX)

\section{AUTHOR INFORMATION}

\section{Corresponding Author}

Susanna Andreasi Bassi - Department of Environmental Engineering, Technical University of Denmark, DK-2800 Kongens Lyngby, Denmark; European Commission, Joint Research Centre, 41092 Seville, Spain; (1) orcid.org/00000001-6052-0233; Email: suan@env.dtu.dk

\section{Authors}

Davide Tonini - European Commission, Joint Research Centre, 41092 Seville, Spain

Hans Saveyn - European Commission, Joint Research Centre, 41092 Seville, Spain

Thomas Fruergaard Astrup - Department of Environmental Engineering, Technical University of Denmark, DK-2800 Kongens Lyngby, Denmark

Complete contact information is available at: https://pubs.acs.org/10.1021/acs.est.1c00761

\section{Author Contributions}

The manuscript was written through the contributions of all authors. All authors have given approval to the final version of the manuscript.

\section{Notes}

The views expressed in the article are the sole responsibility of the authors and in no way represent the view of the European Commission and its services.

The authors declare no competing financial interest.

\section{ACKNOWLEDGMENTS}

The authors would like to thank all people who provided information on PET markets, especially Cristian Crépet from Petcore. Special thanks also to Kimon Keramidas for the data on future projections of energy consumption in the world.

\section{ABBREVIATIONS}

BAU business-as-usual

CC climate change

CLCC conventional life-cycle costing

FTE full-time employees

LCA life-cycle assessment

LCC life-cycle costing

PET poly(ethylene terephthalate)

PMF particulate matter formation

SLCC societal life-cycle costing

SSP solid-state polymerization

\section{REFERENCES}

(1) PlasticsEurope. Plastics: A Story of More Than 100 Years of Innovation. https://www.plasticseurope.org/en/about-plastics/whatare-plastics/history (accessed May 19, 2020).

(2) NobelPrize.org. Award Ceremony Speech. Presentation Speech by Professor A. Fredga, Member of the Nobel Committee for Chemistry of the Royal Academy of Sciences. The Nobel Prize in Chemistry 1963. https://www.nobelprize.org/prizes/chemistry/ 1963/ceremony-speech/ (accessed May 19, 2020).

(3) Chalmin, P. The History of Plastics: From the Capitol to the Tarpeian Rock. Field Actions Sci. Rep. 2019, 19, 6-11.

(4) How Petrochemicals Are Fuelling Oil Demand. Financial Times, 2018

(5) IEA. The Future of Petrochemicals - Towards More Sustainable Plastics and Fertilisers - Executive Summary, 2018.

(6) Barthes, R. Mythologies, 1991st ed.; Noonday: USA, 1957. 
(7) Jambeck, J. R.; Geyer, R.; Wilcox, C.; Siegler, T. R.; Perryman, M.; Andrady, A.; Narayan, R.; Law, K. L. Plastic Waste Inputs from Land into the Ocean. Science 2015, 347, 768-771.

(8) Plastics and Shallow Water Coral Reefs. Synthesis of the Science for Policy-Makers; In Sweet, M.; Stelfox, M.; Lamb, J., Eds.; United Nations, 2019.

(9) Hook, L.; Reed, J. Why the World's Recycling System Stopped Working. https://www.ft.com/content/360e2524-d71a-11e8-a85433d6f82e62f8 (accessed May 19, 2020).

(10) A European Strategy for Plastics in a Circular Economy; European Commission: Brussels, Belgium, 2018.

(11) MacArthur, E. What is the Circular Economy? https://www. ellenmacarthurfoundation.org/circular-economy/what-is-the-circulareconomy (accessed September 25, 2020).

(12) Arena, U.; Mastellone, M. L.; Perugini, F. Life Cycle Assessment of a Plastic Packaging Recycling System. Int. J. Life Cycle Assess. 2003, 8, 92-98.

(13) Chilton, T.; Burnley, S.; Nesaratnam, S. A Life Cycle Assessment of the Closed-Loop Recycling and Thermal Recovery of Post-Consumer PET. Resour. Conserv. Recycl. 2010, 54, 1241-1249.

(14) Huysman, S.; Debaveye, S.; Schaubroeck, T.; Meester, S. De.; Ardente, F.; Mathieux, F.; Dewulf, J. The Recyclability Benefit Rate of Closed-Loop and Open-Loop Systems: A Case Study on Plastic Recycling in Flanders. Resour. Conserv. Recycl. 2015, 101, 53-60.

(15) Rigamonti, L.; Grosso, M.; Møller, J.; Martinez Sanchez, V.; Magnani, S.; Christensen, T. H. Environmental Evaluation of Plastic Waste Management Scenarios. Resour. Conserv. Recycl. 2014, 85, 4253.

(16) Shonfield, P. LCA of Management Options for Mixed Waste Plastics; WRAP, 2008.

(17) Shen, L.; Worrell, E.; Patel, M. K. Open-Loop Recycling: A LCA Case Study of PET Bottle-to-Fibre Recycling. Resour. Conserv. Recycl. 2010, 55, 34-52.

(18) Van Eygen, E.; Laner, D.; Fellner, J. Integrating HighResolution Material Flow Data into the Environmental Assessment of Waste Management System Scenarios - the Case of Plastic Packaging in Austria. Environ. Sci. Technol. 2018, 52, 10934-10945.

(19) Antonopoulos, I.; Faraca, G.; Tonini, D. Recycling of PostConsumer Plastic Packaging Waste in the EU: Recovery Rates, Material Flows, and Barriers. Waste Manage. 2021, 126, 694-705.

(20) Deloitte Sustainability. Blueprint for Plastics Packaging Waste: Quality Sorting \& Recycling, Final Report, 2017.

(21) EC. Directive (EU) 2018/852 of the European Parliament and of the Council of 30 May 2018 Amending Directive 94/62/EC on Packaging and Packaging Waste. Off. J. Eur. Union 2018, 141-154.

(22) Andreoni, V.; Saveyn, H. G. M.; Eder, P. Polyethylene Recycling: Waste Policy Scenario Analysis for the EU-27. J. Environ. Manage. 2015, 158, 103-110.

(23) Hestin, M.; Faninger, T.; Milios, L. Increased EU Plastics Recycling Targets: Environmental, Economic and Social Impact Assessment; Plastic Recyclers Europe: Deloitte, 2015.

(24) Tallentire, C. W.; Steubing, B. The Environmental Benefits of Improving Packaging Waste Collection in Europe. Waste Manage. 2020, 103, 426-436.

(25) Gibbs, A.; Elliott, T.; Vergunst, T.; Ballinger, A.; Hogg, D.; Gentil, E.; Fischer, C.; Bakas, I. Development of a Modelling Tool on Waste Generation and Management" Headline Project. Final Report for the European Commission DG Environment under Framework Contract No ENV.C.2/FRA/2011/0020; The European Commission, Bristol, UK, 2014.

(26) European Environment Agency. The Plastic Waste Trade in the Circular Economy. https://www.eea.europa.eu/themes/waste/ resource-efficiency/the-plastic-waste-trade-in (accessed May 19, 2020).

(27) EC. Directive (EU) 2019/904 of the European Parliament and of the Council of 5 June 2019 on the Reduction of the Impact Fof Certain Plastic Products on the Environment. Off. J. Eur. Union 2019, $155,1$.
(28) Petcore Europe Profile, Activities \& Benefits - PET Is the Most Recycled Plastics Packaging; Petcore Europe: Brussels, Belgium, 2019.

(29) EEA. EEA Glossary. https://www.eea.europa.eu/help/ glossary/eea-glossary/cradle-to-grave (accessed September 25, 2021).

(30) ISO 14040:2006. Environmental Management - Life Cycle Assessment - Principles and Framework; European Committee for Standardization: Brussels, Belgium, 2006.

(31) ISO 14044:2006. Environmental Management - Life Cycle Assessment - Requirements and Guidelines; European Committee for Standardization: Brussels, Belgium, 2006.

(32) ISO 14049:2000. Environmental Management - Life Cycle Assessment - Examples of Application of ISO 14041 to Goal and Scope Definition and Inventory Analysis; European Committee for Standardization: Brussels, Belgium, 2000.

(33) Swarr, T. E.; Hunkeler, D.; Klöpffer, W.; Pesonen, H.-L.; Ciroth, A.; Brent, A. C.; Pagan, R. "Environmental Life Cycle Costing": A Code of Practise; Society of Environmental Toxicology and Chemistry (SETAC): Pensacola, FL, 2011.

(34) Martinez-Sanchez, V. Integrated Environmental and Economic Assessment of Waste Management Systems. Ph,D. Thesis, Technical University of Denmark, 2016.

(35) Martinez-Sanchez, V.; Kromann, M. A.; Astrup, T. F. Life Cycle Costing of Waste Management Systems: Overview, Calculation Principles and Case Studies. Waste Manage. 2015, 36, 343-355.

(36) Clavreul, J.; Baumeister, H.; Christensen, T. H.; Damgaard, A. An Environmental Assessment System for Environmental Technologies. Environ. Model. Softw. 2014, 60, 18-30.

(37) Easetech. DTU Environment. http://www.easetech.dk/ (accessed April 14, 2020).

(38) Wernet, G.; Bauer, C.; Steubing, B.; Reinhard, J.; Moreno-Ruiz, E.; Weidema, B. The Ecoinvent Database Version 3 (Part I): Overview and Methodology. Int. J. Life Cycle Assess. 2016, 21, 12181230.

(39) Ekvall, T.; Weidema, B. P. System Boundaries and Input Data in Consequential Life Cycle Inventory Analysis. Int. J. Life Cycle Assess. 2004, 9, 161-171.

(40) Weidema, B. Market Information in Life Cycle Assessment, 2003. (41) Weidema, B. ISO System Expansion = Substitution. https:// lca-net.com/blog/iso-system-expansion-substitution/ (accessed August 14,2021$)$.

(42) Huijbregts, M.; Steinmann, Z. J. N.; Elshout, P. M. F. M.; Stam, G.; Verones, F.; Vieira, M. D. M.; Zijp, M.; van Zelm, R. ReCiPe 2016 - A Harmonized Life Cycle Impact Assessment Method at Midpoint and Endpoint Level Report I: Characterization, 2016.

(43) Huijbregts, M. A. J.; Steinmann, Z. J. N.; Elshout, P. M. F.; Stam, G.; Verones, F.; Vieira, M.; Zijp, M.; Hollander, A.; van Zelm, R. ReCiPe2016: A Harmonised Life Cycle Impact Assessment Method at Midpoint and Endpoint Level. Int. J. Life Cycle Assess. 2017, 22, 138-147.

(44) Climate Change 2013: The Physical Science Basis. In Contribution of Working Group I to the Fifth Assessment Report of the Intergovernmental Panel on Climate Change; Stocker, T. F.; Qin, D.; Plattner, G. K.; Tignor, M.; Allen, S. K.; Boschung, J.; Nauels, A.; Xia, Y.; Bex, V.; Midgley, P. M., Eds.; IPCC, 2013.

(45) van Zelm, R.; Preiss, P.; van Goethem, T.; Van Dingenen, R.; Huijbregts, M. Regionalized Life Cycle Impact Assessment of Air Pollution on the Global Scale: Damage to Human Health and Vegetation. Atmos. Environ. 2016, 134, 129-137.

(46) Cherubini, F.; Peters, G. P.; Berntsen, T.; Strømman, A. H.; Hertwich, E. CO2 Emissions from Biomass Combustion for Bioenergy: Atmospheric Decay and Contribution to Global Warming. GCB Bioenergy 2011, 3, 413-426.

(47) Faraca, G.; Tonini, D.; Astrup, T. F. Dynamic Accounting of Greenhouse Gas Emissions from Cascading Utilisation of Wood Waste. Sci. Total Environ. 2019, 651, 2689-2700.

(48) De Bruyn, S.; Bijleveld, M.; de Graaff, L.; Schep, E.; Schroten, A.; Vergeer, R.; Ahdour, S. Environmental Prices Handbook EU28 Version - Methods and Numbers for Valuation of Environmental Impacts, 2018. 
(49) Vejledning i Samfundsøkono Miske Konsekvens Vurderinger; Finansministeriet - Center for Konkurrence, Selskaber Og Forsyning: Copenhagen, Denmark, 2017.

(50) Eurostat. HICP - Inflation Rate. https://ec.europa.eu/ eurostat $/ \mathrm{tgm} /$ table.do? tab $=$ table \&init $=1 \&$ language $=$ en $\&$ pcode $=$ tec00118\&plugin $=1$ (accessed May 25, 2020).

(51) Cimpan, C.; Maul, A.; Wenzel, H.; Pretz, T. Techno-Economic Assessment of Central Sorting at Material Recovery Facilities - The Case of Lightweight Packaging Waste. J. Cleaner Prod. 2016, 112, 4387-4397.

(52) Pujari, A. Highlights of a Strong Growth Market - Polyester Fibers \& PET; IHS Market: Houston, TX, 2018.

(53) Assessment of Separate Collection Schemes in the 28 Capitals of the EU - Reference: 070201/ENV/2014/691401/SFRA/A2; EC: Brussels, Belgium, 2015.

(54) PET Bottle Flake Decontamination Processes to Achieve Approval for Direct Food Contact, 4th China Int'l Recycled Polyester Fiber Market \& Tech Forum, Hangzhou, Zhejiang Province, China, 2008; pp $1-20$.

(55) Recycling Technology for PET Flakes; Starlinger: Vienna, Austria, 2013.

(56) European Commission. Municipal Waste Statistics. http://ec. europa.eu/eurostat/statistics-explained/index.php/Municipal_waste_ statistics (accessed March 2, 2016).

(57) EC. Directive (EU) 2018/850 of the European Parliament and of the Council of 30 May 2018 Amending Directive 1999/31/EC on the Landfill of Waste. Off. J. Eur. Union, 2018.

(58) EC. Commission Decision of 18 November 2011 Establishing Rules and Calculation Methods for Verifying Compliance with the Targets Set in Article 11(2) of Directive 2008/98/EC of the European Parliament and of the Council. Off. J. Eur. Union 2011, 310, No. 11.

(59) ICIS. ICIS and Petcore Europe Annual Survey on the European PET Recycle Industry 2017, 2018.

(60) Petcore Europe. Petcore Europe 2025 - Pledge for the PET Value Chain to Increase Circularity and Recycling, 2019.

(61) Eunomia. PET Market in Europe. State of Play. Production, Collection and Sorting Data, 2020.

(62) Geyer, R.; Jambeck, J. R.; Law, K. L. Production, Use, and Fate of All Plastics Ever Made. Sci. Adv. 2017, 3, 25-29.

(63) Bisinella, V.; Conradsen, K.; Christensen, T. H.; Astrup, T. F. A Global Approach for Sparse Representation of Uncertainty in Life Cycle Assessments of Waste Management Systems. Int. J. Life Cycle Assess. 2016, 21, 378-394.

(64) Clavreul, J.; Guyonnet, D.; Christensen, T. H. Quantifying Uncertainty in LCA-Modelling of Waste Management Systems. Waste Manage. 2012, 32, 2482-2495.

(65) Wood Mackenzie PCI. In Product Development in MMF: Is Cotton Able to Compete? 33rd International Cotton Conference Bremen, Bremen, Germany, 2016.

(66) Keramidas, K.; Tchung-Ming, S.; Diaz-Vazquez, A. R.; Weitzel, M.; Vandyck, T.; Després, J.; Schmitz, A.; Rey Los Santos, L.; Wojtowicz, K.; Schade, B.; Saveyn, B.; Soria-Ramirez, A. Global Energy and Climate Outlook 2018: Sectoral Mitigation Options towards a LowEmissions Economy - Global Context to the EU Strategy for Long-Term Greenhouse Gas Emissions Reduction. EUR 29462 EN, 2018.

(67) Nessi, S.; Bulgheroni, C.; Garbarino, E.; Garcia-Gutierrez, P.; Orveillon, G.; Sinkko, T.; Tonini, D.; Pant, R. Environmental Sustainability Assessment Comparing through the Means of Lifecycle Assessment the Potential Environmental Impacts of the Use of Alternative Feedstock (Biomass, Recycled Plastics, $\mathrm{CO}_{2}$ ) for Plastic Articles in Comparison to Using [...] - Part 2, 2018.

(68) PET Market in Europe, State of Play - Production, Collection and Recycling Data; EFBW, Petcore Europe, Plastics Recyclers Europe: Brussels, Belgium, 2020.

(69) Tonini, D.; Garcia-Gutierrez, P.; Nessi, S. Environmental Effects of Plastic Waste Recycling Effects - EUR 30668 EN, 2021.

(70) Ekvall, T.; Gottfridsson, M.; Nilsson, J.; Nellström, M.; Rydberg, M.; Rydberg, T. Incentives for Recycling and Incineration in
LCA: Polymers in Product Environmental Footprints; Swedish Life Cycle Center: Gothenburg, Sweden, 2021.

(71) Ekvall, T.; Gottfridsson, M.; Nellström, M.; Nilsson, J.; Rydberg, M.; Rydberg, T. Incentives for Recycling and Incineration in LCA Results: Polymers in Product Environmental Footprints. Waste Manage. 2021, 136, 153-161.

(72) Andreasi Bassi, S.; Tonini, D.; Ekvall, T.; Astrup, T. F. A Life Cycle Assessment Framework for Large-Scale Changes in Material Circularity. Waste Manage. 2021, 135, 360-371.

(73) Beaumont, N. J.; Aanesen, M.; Austen, M. C.; Börger, T.; Clark, J. R.; Cole, M.; Hooper, T.; Lindeque, P. K.; Pascoe, C.; Wyles, K. J. Global Ecological, Social and Economic Impacts of Marine Plastic. Mar. Pollut. Bull. 2019, 142, 189-195.

(74) Viool, V.; Gupta, A.; Petten, L.; Schalekamp, J. The Price Tag of Plastic Pollution. An Economic Assessment of River Plastic; Deloitte: The Netherlands, 2019.

(75) Downey, R. Global Packaging: Sizing Demand and Opportunities for PET Bottles, 2016.

(76) Packaging Europe. PET Plastic Bottle Consumption Set to Grow by 3.9\% Over the Next Five Years. https://packagingeurope. com/pet-plastic-bottle-consumption-set-to-grow/ (accessed April 14, 2020).

(77) Staub, C. Markets Update: Asian Countries Further Limit Plastic Imports. https://resource-recycling.com/plastics/2018/08/ 22/markets-update-asian-countries-further-limit-plastic-imports/ (accessed April 14, 2020).

(78) BBC News. Why Some countries are Shipping Back Plastic Waste. https://www.bbc.com/news/world-48444874 (accessed April 14, 2020)

(79) The New Plastics Economy. Rethinking the Future of Plastics; World Economic Forum, 2016.

(80) Pilz, H.; Brandt, B.; Fehringer, R. The Impact of Plastic Packaging on Life Cycle Energy Consumption and Greenhouse Gas Emissions in Europe. Summary Report; Vienna, Austria, 2010.

(81) D’Alessandro, S.; Cieplinski, A.; Distefano, T.; Dittmer, K Feasible Alternatives to Green Growth. Nat. Sustainability 2020, 3, 329-335. 